Richard D. Branson Bryce R. H. Robinson

\title{
Oxygen: when is more the enemy of good?
}

Received: 20 July 2010

Accepted: 7 August 2010

Published online: 28 September 2010

(C) Copyright jointly held by Springer and ESICM 2010

R. D. Branson (凶) • B. R. H. Robinson

Division of Trauma and Critical Care, Department of Surgery, University of Cincinnati, 231 Albert Sabin Way,

Cincinnati, OH 45267-0558, USA

e-mail: richard.branson@uc.edu

Tel.: +1-513-5586785

Fax: +1-513-5583747

B. R. H. Robinson

e-mail: Bryce.Robinson@uc.edu stromalites (formation of algal plankton), which excreted it at least 2.3 billion years ago. Since then sediments have been rusted or oxidized. Oxygen is toxic. It rusts a person in a century or less. With oxygen came the danger and blessing of fire. If introduced today, this gas might have difficulty getting approved by the Food and Drug Administration."

In the intensive care unit, oxygen toxicity during mechanical ventilation is presumed to occur at levels exceeding 0.40 . Oxygen is rarely a single factor to produce lung injury. Pulmonary oxygen toxicity is associated with aggressive ventilation, time, and inspired oxygen concentration $\left(\mathrm{FIO}_{2}\right)$ [2-5]. Hyperoxia of the lung is presumed to precipitate lung injury through the production of reactive oxygen intermediates [6]. Experimental models of hyperoxic lung injury demonstrate endothelial cell injury, an increase in pulmonary capillary permeability, and a marked increase in inflammatory cells [5].

From a clinician's perspective, the reduction of $\mathrm{FIO}_{2}$ to safe levels through the appropriate use of positive end expiratory pressure (PEEP) and manipulation of mean airway pressure is a common and appropriate goal. The ARDSnet ARMA trial utilized a minimum $\mathrm{FIO}_{2}$ of 0.35 and PEEP of $5 \mathrm{cmH}_{2} \mathrm{O}$. The PEEP/FIO $/ \mathrm{O}_{2}$ table was developed through expert opinion with knowledge that treated patients would enter the trial with a $\mathrm{PaO}_{2} / \mathrm{FIO}_{2}<200 \mathrm{mmHg}$ [7]. The more aggressive ARDSnet ALVEOLI trial maintained a lower $\mathrm{FIO}_{2}$ through manipulation of PEEP, but found no differences in outcomes [8]. Historically, a higher $\mathrm{FIO}_{2}$ limit often prevents hypoxemia during ICU manipulations and is below the threshold for pulmonary oxygen toxicity.

In this issue of Intensive Care Medicine, de Graaff and colleagues [9] demonstrate that Dutch clinicians appear to be guided by the concept of minimizing $\mathrm{FIO}_{2}$ to levels that are presumed to be non-toxic with little regard for arterial oxygenation $\left(\mathrm{PaO}_{2}\right)$. Their population of predominantly surgical patients (including cardiothoracic 
and neurosurgical) typically do not require high $\mathrm{FIO}_{2}$ to maintain arterial normoxemia. The group demonstrated that if $\mathrm{FIO}_{2}$ was $\leq 0.40$ and PEEP was $5 \mathrm{cmH}_{2} \mathrm{O}$, even in the presence of hyperoxemia $\left(\mathrm{PaO}_{2}>120 \mathrm{mmHg}\right)$ reductions in $\mathrm{FIO}_{2}$ were only made in $22 \%$ of cases. In the presence of hyperoxemia and an $\mathrm{FIO}_{2}>0.40, \mathrm{FIO}_{2}$ or PEEP changes were made in $65-82 \%$ of cases, with higher $\mathrm{FIO}_{2}$ resulting in the most frequent changes. These findings suggest that while there is concern about pulmonary toxicity caused by hyperoxic gas mixtures administered to the lungs, there appears to be little concern for hyperoxemia.

The article by de Graaff raises more questions than it answers. Even today, we still do not know what constitutes a safe $\mathrm{FIO}_{2}$. Data from animal studies and the collective ICU experience over the last 40 years suggest that an $\mathrm{FIO}_{2}<0.40$ is non-toxic. The data from de Graaff et al. beg the question, should $\mathrm{FIO}_{2}$ continue to be decreased in the face of hyperoxemia? Clearly, there is no advantage to oxygen delivery by elevated $\mathrm{PaO}_{2}$ under normobaric conditions. Exceeding the required $\mathrm{FIO}_{2}$ to create normoxemia may also mask the presence of worsening pulmonary function [10]. At a $\mathrm{PaO}_{2}$ of $120 \mathrm{mmHg}$ and oxygen saturation of 99\%, a fall in $\mathrm{PaO}_{2}$ of $50 \%$ would still provide an $\mathrm{SaO}_{2}$ of $\geq 90 \%$. In this instance, pulse oximetry goals would not be violated, and there would be no warning of a significant decrease in pulmonary dysfunction.

Lung injury occurs over a wide spectrum requiring individualized oxygen requirements and mechanical ventilation needs. Our recent work in closed loop control of oxygenation demonstrates that even severely injured trauma patients (injury severity score $>25$ ) can frequently be managed immediately postoperatively with an $\mathrm{FIO}_{2}$ $<0.30$. In a number of cases, these patients have had $\mathrm{PaO}_{2}$ $>80 \mathrm{mmHg}$ on an $\mathrm{FIO}_{2}$ of 0.21 [11]. These data have important implications for military care in austere conditions where oxygen is a limited resource. In contrast, civilian hospitalists rarely worry if their oxygen supply will run out.

A growing body of evidence suggests that hyperoxemia may result in worse outcomes in a number of conditions.
Kilgannon et al. reported results of a multi-center trial comparing outcomes in patients after non-traumatic cardiac arrest based on $\mathrm{PaO}_{2}$. They showed that hyperoxemia $\left(\mathrm{PaO}_{2} \geq 300 \mathrm{mmHg}\right)$ was associated with increased mortality compared to both the normoxemic $\left(\mathrm{PaO}_{2}\right.$ $\leq 300 \mathrm{mmHg} \geq 61 \mathrm{mmHg}$ ) and the hypoxemic group $\left(\mathrm{PaO}_{2} \leq 60 \mathrm{mmHg}\right)$ [12]. These findings support earlier animal studies of hyperoxemia following experimental cardiac arrest. In a recent systematic review of oxygen use in the treatment of myocardial infarction, Wijesinghe and colleagues [13] found few studies with significant power to evaluate the safety of oxygen therapy. However, several studies suggest that hyperoxemia may result in vasoconstriction in the coronary circulation and hemodynamic instability [14-17]. These studies do not dissuade the use of oxygen following myocardial infarction, but rather reinforce the need for the titration of oxygen to a normal saturation. The concept of oxygen titration is gaining traction. Recent work with severe traumatic brain injury suggests that both hypoxemia and hyperoxemia are associated with increased mortality and disposition [18]. This is in conflict with the current trend of using hyperoxemia to achieve acceptable levels of brain tissue $\mathrm{PO}_{2}$ when the deleterious effects of hypoxemia in this population are well described.

The work of de Graaff et al. suggests that $\mathrm{FIO}_{2}$ titration might best be accomplished using a goal $\mathrm{PaO}_{2} / \mathrm{FIO}_{2}$ ratio with a lower limit of $\mathrm{FIO}_{2}$ set at 0.21 . It also reminds us that, despite the fact that oxygen is ubiquitous in the hospital and easily delivered, often without a physician order, it is a drug that should be titrated to the desired effect. Both hypoxemia and hyperoxemia have consequences beyond pulmonary oxygen toxicity.

The discovery of oxygen is an interesting account of several investigators arriving at the same conclusion around 1773-1774. Before Lavoisier coined the term 'oxygen' it had been called 'nitro ariel spirits,' 'dephlogisticated air,' 'fire air,' and 'eminently breathable air' [19]. As oxygen nears its 250th birthday, it is time to treat it as an important drug with consequences for both under and over dosing.

\section{References}

1. Servinghaus JW, Astrup PB (1986) History of blood gas analysis: IV Leland Clark's oxygen electrode. J Clin Monit 2:125-139

2. Bailey TC, Martin EL, Zhao L, Veldhuizen RA (2003) High oxygen concentrations predispose mouse lungs to the deleterious effects of high stretch ventilation. J Appl Physiol 94:975-982
3. Davis JM, Penney DP, Notter RH, Metlay L, Dickerson B, Shapiro DL (1989) Lung injury in the neonatal piglet caused by hyperoxia and mechanical ventilation. J Appl Physiol 67:1007-1012

4. Quinn DA, Moufarrej RK, Volokhov A, Hales CA (2002) Interactions of lung stretch, hyperoxia, and MIP-2 production in ventilator-induced lung injury. J Appl Physiol 93:517-525
5. Sinclair SE, Altemeier WA, MatuteBello G, Chi EY (2004) Augmented lung injury due to interaction between hyperoxia and mechanical ventilation. Crit Care Med 32:2496-2501

6. Altemeier WA, Scott SE (2007) Hyperoxia in the intensive care unit: why more is not always better. Curr Opin Crit Care 13:73-78 
7. The Acute Respiratory Distress Syndrome Network (2000) Ventilation with lower tidal volumes as compared with traditional tidal volumes for acute lung injury and the acute respiratory distress syndrome. N Engl J Med 342:1301-1308

8. NHLBI Acute Respiratory Distress Syndrome Network (2004) Higher versus lower positive end-expiratory pressures in patients with the acute respiratory distress syndrome. N Engl J Med 351:327-336

9. de Graaff AE, Dongelmans DA, Binnekade JM, de Jonge E (2011) Clinicians response to hyperoxia in ventilated patients in a Dutch ICU depends on the level of $\mathrm{FIO}_{2}$. Intensive Care Med. doi: 10.1007/s00134-010-2025-z

10. Downs JB (2006) Is supplemental oxygen necessary? J Cardiothorac Vasc Surg 20:133-135

11. Johannigman JA, Branson RD, Edwards MG (2009) Closed loop control of inspired oxygen concentration in trauma patients. J Am Coll Surg 208:763-768
12. Kilgannon JH, Jones AE, Shapiro NI Angelos MG, Milcarek B, Hunter K, Parrillo JE, Trzeciak S, Emergency Medicine Shock Research Network (EMShockNet) Investigators (2010) Association between arterial hyperoxia following resuscitation from cardiac arrest and in-hospital mortality. JAMA 202:2165-2171

13. Wijesinghe M, Perrin K, Ranchord A, Simmonds M, Weatherall M, Beasley R (2009) Routine use of oxygen in the treatment of myocardial infarction: systematic review. Heart 95:198-202

14. Verecki V, Martin E, Rosenthal RE, Hof PR, Hoffman GE, Fiskum G (2006) Normoxic resuscitation after cardiac arrest protects against hippocampal oxidative stress, metabolic dysfunction and neuronal death. J Cereb Blood Flow Metab 26:821-835

15. Balan IS, Fiskum G, Hazelton J, Cotto-Cumba C, Rosenthal RE (2006) Oximetry guided reoxygenation improves neurologic outcome after experimental cardiac arrest. Stroke 37:3008-3013
16. McNulty PH, King N, Scott S, Hartman G, McCann J, Kozak M, Chambers CE, Demers LM, Sinoway LI (2005) Effects of supplemental oxygen administration on coronary blood flow in patients undergoing cardiac catheterization. Am J Physiol Heart Circ Physiol 288:H1057-H1062

17. Davidson RM, Ramo BW, Wallace AG, Whalen RE, Starmer CF (1973) Blood gas and hemodynamic responses to oxygen in acute myocardial infarction. Circulation 47:704-711

18. Davis DP, Meade W, Sise MJ (2009) Both hypoxemia and extreme hyperoxemia may be detrimental in patients with severe traumatic brain injury. J Neurotrauma 26:2217-2223

19. Severinghaus JW (2002) Priestly, the furious free thinker of the enlightenment, and Scheele, the taciturn apothecary of Uppsala. Acta Anesth Scand 46:2-9 